University of Nebraska - Lincoln

DigitalCommons@University of Nebraska - Lincoln

3-25-2021

\title{
Seasonal variation in the effects of urban environmental factors on land surface temperature in a winter city
}

Wen Wu

Lidong Li

Chunlin Li

Follow this and additional works at: https://digitalcommons.unl.edu/usdaarsfacpub

Part of the Agriculture Commons

This Article is brought to you for free and open access by the U.S. Department of Agriculture: Agricultural Research Service, Lincoln, Nebraska at DigitalCommons@University of Nebraska - Lincoln. It has been accepted for inclusion in Publications from USDA-ARS / UNL Faculty by an authorized administrator of DigitalCommons@University of Nebraska - Lincoln. 


\title{
Seasonal variation in the effects of urban environmental factors on land surface temperature in a winter city
}

\author{
Wen $\mathrm{Wu}^{\mathrm{a}}$, Lidong $\mathrm{Li}^{\mathrm{b},{ }^{*}}$, Chunlin $\mathrm{Li}^{\mathrm{c}, * *}$ \\ a JangHo Architecture College, Liaoning Provincial Key Laboratory of Urban and Architectural Digital Technology, Northeastern University, Shenyang, \\ 110819, China \\ ${ }^{\mathrm{b}}$ USDA-ARS, Agroecosystem Management Research Unit, 251 Filley Hall, UNL-East Campus, Lincoln, NE, 68583, USA \\ ${ }^{\mathrm{c}}$ Key Laboratory of Forest Ecology and Management, Institute of Applied Ecology, Chinese Academy of Sciences, Shenyang, 110016, China
}

\section{A R T I C L E I N F O}

\section{Article history:}

Received 25 January 2021

Received in revised form

20 March 2021

Accepted 25 March 2021

Available online 30 March 2021

Handling editor: Prof. Jiri Jaromir Klemeš

\section{Keywords:}

Urban thermal environment

Distance from green space

Distance from water body

Structural equation model (SEM)

Northeast China

\begin{abstract}
A B S T R A C T
Environmental factors such as urban landscape patterns, local climate, topography, and socioeconomic conditions have significant impacts on land surface temperature (LST), especially through the urban heat island effect. At present, in-depth studies on the mechanisms determining LST in different seasons in winter cities are lacking. In this study, we used structural equation modeling for 12 environmental factors to characterize how these factors affect the temporal and spatial heterogeneity of the LST in the winter city of Shenyang, China. We found that the most critical factors affecting LST varied with season. Specifically, the distances from the nearest water body and nearest green space had the largest impacts on the LST in spring and summer, with path coefficients of 0.51 and 0.19 for spring and 0.42 and 0.21 for summer, respectively. In winter, the main factors affecting LST were elevation, slope, and population density, with respective path coefficients of $-0.5,-0.41$, and 0.29 . Our findings suggest that the urban thermal environment in this winter city can be improved by: optimizing the landscape pattern of green spaces and water bodies; and reducing the population density by establishing satellite cities. This study highlights how landscape pattern can be used to regulate the urban thermal environment and mitigate predicted climate change impacts on the quality, health, and safety of urban living.
\end{abstract}

Published by Elsevier Ltd.

\section{Introduction}

Rapid urbanization has caused fundamental changes in urban climate, and issues associated with the urban thermal environment have become more prominent (Yang et al., 2020a). Further, it is expected that the effect of urbanization on the spatial morphology of landscapes will further exacerbate the magnitude and complexity of urban thermal dynamics (White et al., 2012; Hu, 2019). Growing world populations and the rapid development of the construction industry led to the three-dimensional expansion of urban areas (Luan et al., 2020), closely relating to the urban heat island (UHI) effect and subsequently changing land surface radiation cycles. Climate change has increased the frequency of heat waves, and other weather extremes (Meehl and Tebaldi, 2004), affecting the quality of the urban living environment and the health

\footnotetext{
* Corresponding author.

** Corresponding author.

E-mail addresses: lidong.li@usda.gov (L. Li), lichunlin@iae.ac.cn (C. Li).
}

and safety of residents. Developing evidence-based strategies for planning, construction, and management to address the challenges linked to a changing urban thermal environment is an urgent problem for municipal governments and planners (Yao et al., 2018).

Land surface temperature (LST) is usually represented as the air temperature at $2 \mathrm{~m}$ from the ground measured by a weather station (Tian et al., 2019; Zeng et al., 2015). LST varies by location and environment, and is an indicator of the surface energy balance which drives the UHI effect. A review by Jiang et al. (2020) showed that station observations (42.5\% of the literature), model simulations $(38.3 \%)$, and mobile measurements $(19.2 \%)$ were the main methods of obtaining LST data. In reality, the limited number of non-uniformly dispersed weather stations cannot completely represent the spatial variations in LST for large scales (Huang and Wang, 2019). While the proportion of model simulation methods has increased year by year, the emergence of remote sensing technology has allowed long-term monitoring of the LST over large continuous spaces (Kuang et al., 2015), with satellite thermal infrared remote sensing being the primary means of obtaining LST (86.5\%) (Jiang et al., 2020). 
There are abundant data on the correlation between LST and urban land-use type, but the seasonal dynamics of LST are seldom considered, resulting in a knowledge gap in how temporal and spatial environmental factors interact with each other to affect the formation of UHIs (Chen et al., 2012; Du et al., 2016; Peng et al., 2018), particularly in winter cities (Guo et al., 2015). Winter cities are a special urban group in the Northern Hemisphere characterized by long harsh winters (i.e. mean January temperatures below $-18^{\circ} \mathrm{C}$ ). Winter cities also face the cooling demand for urban expansion, and the different seasons have significantly different effects, which is often overlooked in studies (Miles and Esau, 2017). Here, we investigate the seasonal variation of LST and explore how LST is affected by urban morphology in Shenyang, a winter city in northern China.

In addition to the lack of seasonal studies, the relevant research methods also face limitations. In terms of marginal effects, only a few case studies on the marginal effect of urban building patterns on LST have been done in a few subtropical or tropical climatic regions, such as Shanghai, Shenzhen, Hong Kong, and Singapore, while few attentions were paid on winter cities (Peng et al., 2018; Sun et al., 2020; Yu et al., 2020). The marginal effect can provide a quantitative parameter adjustment strategy to improve LST rather correlations between LST and environmental factors (Huang and Wang, 2019). In addition, studies (Shi et al., 2020b; Zhang et al., 2019) have mainly focused on the coupling effect of urban green space, building/impermeable surfaces, and water bodies, most of which used regression models to study urban agglomeration scale or regional scales. There is still a lack of investigations on the impact of internal environmental factors in urban built-up areas.

Here, we used structural equation modeling (SEM) to test the causal relationships between environmental factors and the LST of urban areas and the seasonal variations of those relationships in a winter city (Shenyang, China). We hypothesized that (1) environmental factors would affect LST, and (2) the effect of environmental factors on LST are season-specific. Based on statistical data, 3D building data, Landsat- 8 satellite imagery, a digital elevation model (DEM), and MODIS MOD11A2 product, we grouped 12 environmental predictor variables into four classes including topography, land use types, socioeconomics and building pattern. Finally, SEM is used to verify the hypothesis.

\section{Study description}

\subsection{Study area}

Shenyang is in the northeastern region of China. It is an important heavy industry base of China for the manufacturing of equipment (Wu et al., 2020). The total area of Shenyang is approximately $12,948 \mathrm{~km}^{2}$, of which the urbanized area comprises $3495 \mathrm{~km}^{2}$. At the end of 2019, the resident population was 8.322 million, $81 \%$ of which live in urban areas. The terrain is mainly plains, interspersed by mountains and hills. Shenyang has a typical continental monsoon climate, with a mean annual precipitation in the urban area of $\sim 700 \mathrm{~mm}$, where precipitation is concentrated in the summer and the winter is long, cold, and dry. The mean annual temperature of $8.3^{\circ} \mathrm{C}$ (range -35 to $36^{\circ} \mathrm{C}$ ), with an average January temperature of $-18{ }^{\circ} \mathrm{C}$. Temperature differences are distinct for each of the four seasons, and heating radiators are commonly used from November to April.

Driven by policies such as the "Revitalize the Old Northeast Industrial Bases" and "Establishment of Shenyang Economic Zone" policies, the urban area of Shenyang has undergone large-scale urban transformation, and the density and height of new buildings are constantly increasing. The present study focuses on the urban center of Shenyang, where the Third Ring Road defines the boundary encompassing nine major municipal districts that covers $456 \mathrm{~km}^{2}\left(41^{\circ} 09^{\prime}-41^{\circ} 55^{\prime} \mathrm{N}, 123^{\circ} 16^{\prime}-123^{\circ} 36 \mathrm{E}\right)$. This area represents a typical winter city environment of an industrial metropolis undergoing rapid urbanization.

\subsection{Data sources and preprocessing}

This study included five datasets: (1) statistical data on socioeconomics from the China Urban Statistical Yearbook and the Shenyang Statistical Yearbook (Fig. 1a); (2) 3D building data of Shenyang in 2017 (Fig. 1b); (3) Landsat-8 satellite imagery in 2016 for interpreting land-use type (i.e. urban green space, water body, arable land, industrial land, roads, residential land, bare land, and land for public facilities according to Google Earth v.7.3.3) (Fig. 1c). The sets of imageries were derived from the United States Geological Survey (USGS, https://www.usgs.gov/); (4) DEM derived from the United States Geological Survey (USGS) (Fig. 1d); and (5) seasonal LST in 2016 from the 8-day period MOD11A2 product with a spatial resolution of $1 \mathrm{~km}$ (US National Aeronautics and Space Administration; https://ladsweb.nascom.nasa.gov/search/).

The number of floors was taken from the 3D building data of Shenyang in 2017, and the number of floors was multiplied by $3 \mathrm{~m}$ to obtain the building height. We verified the location and floor height of each building by comparing our data with the historical information in Google Earth Pro, Baidu Panoramic Map, and extraction results from Barista software. The results show that the mean relative error of the building height was less than $2 \mathrm{~m}$, which met our research needs. Meanwhile, due to the limitation of highquality data sources, this study adopted multisource data over a span of one year, and the variation in land use and building height in this year was very small, which was acceptable for the study.

\section{Methods}

\subsection{Retrieving the LST}

Based on the sample transects, Peng et al. (2020) showed that around $1 \mathrm{~km}$ could be used as the prioritizing research scale for simultaneously exploring multiple LST influencing factors. We used the $8 \mathrm{~d}$ LST data from MODIS MOD11A2 product through MVC (Maximum Value Composite) method (Holben, 1986) to obtain the monthly LST data. And then and we calculate the quarterly data by taking the mean value. In this study, LST represents the seasonal average LST at $1 \mathrm{~km}$ resolution, with JJA (June, July, and August) as summer, SON (September, October, and November) as autumn, DJF (December, January, and February) as winter, MAM (March, April, and May) as spring. The downloaded LST products were processed for reprojection and format conversion using the Moderate Resolution Imaging Spectroradiometer (MODIS) Reprojection Tool. To reduce the effect of clouds and fog, MOD11A2 data were used to generate LST using the maximum-value composite to obtain the average for each season in 2016 (Guo et al., 2017; Holben, 1986).

\subsection{Selection of environmental variables}

Considering the results of previous studies and the actual conditions in the study area, four types of environmental factors were selected for evaluating in our urban LST model (Table 1). According to the resolution of LST, spatially uniform sampling was adopted in this study. Samples were selected at $1 \mathrm{~km}^{2}$ intervals in the study area, and 532 effective points were generated spatially and uniformly in ArcGIS 10.2, and the attribute values of each point on each factor layer were extracted. Variance inflation factor (VIF) analysis was performed on 24 environment variables to measure the amount of multicollinearity in this set of variables ( $\mathrm{R}$ v.3.3.3; http:// 


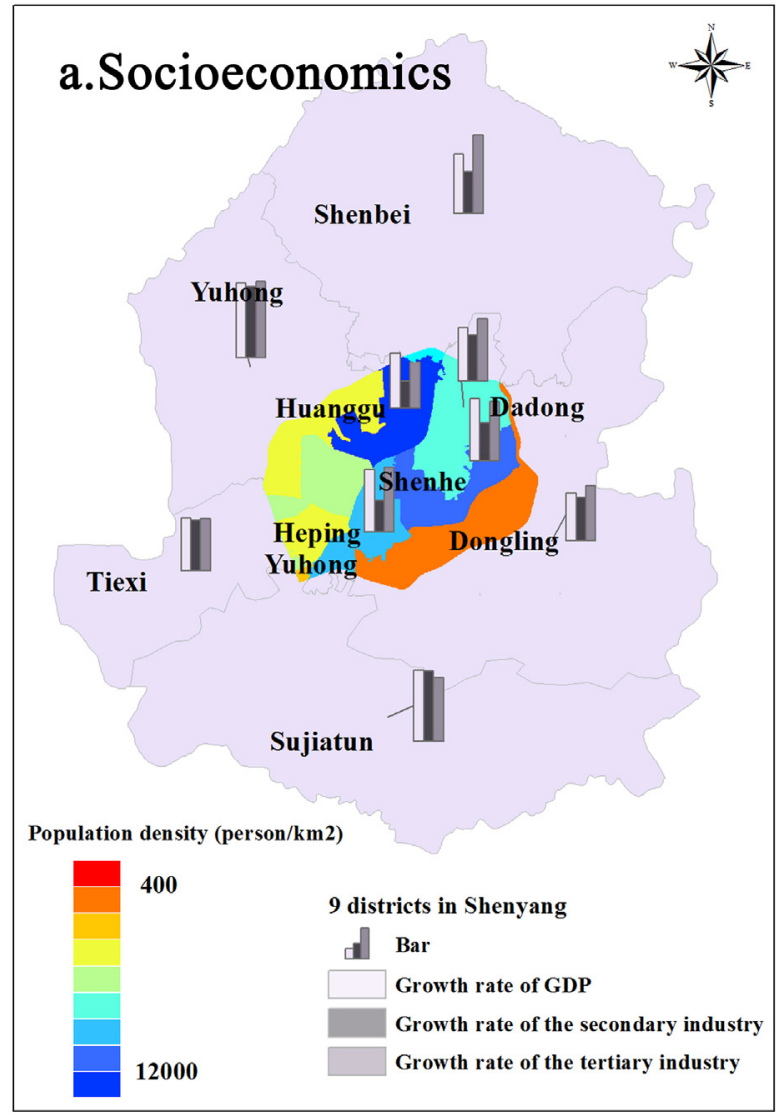

\section{c.Land use types}

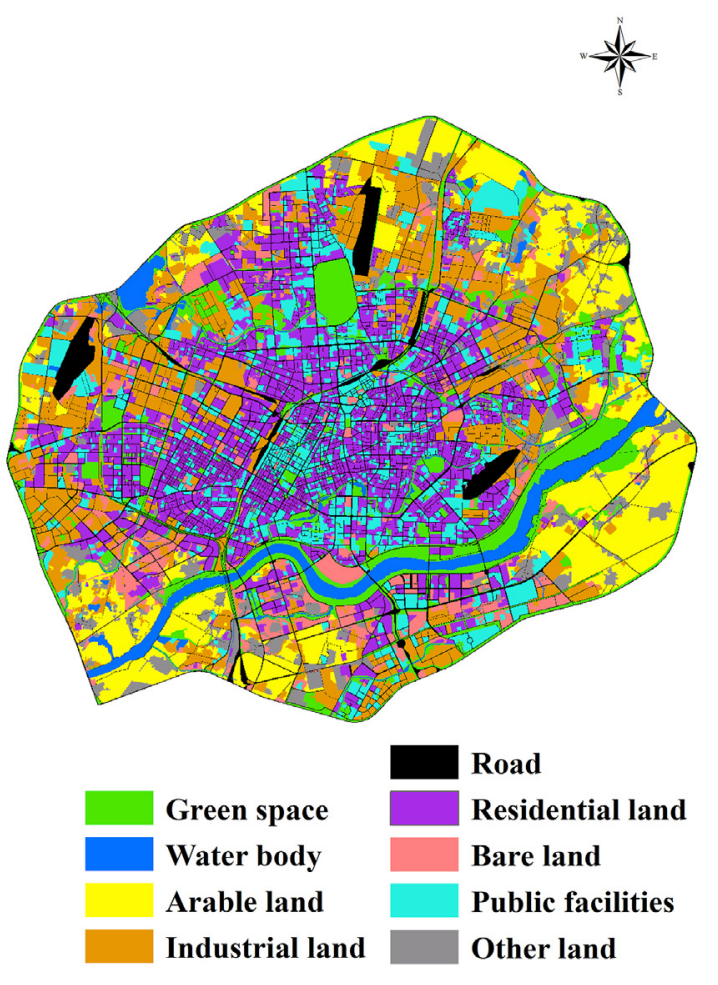

\section{b.Building}

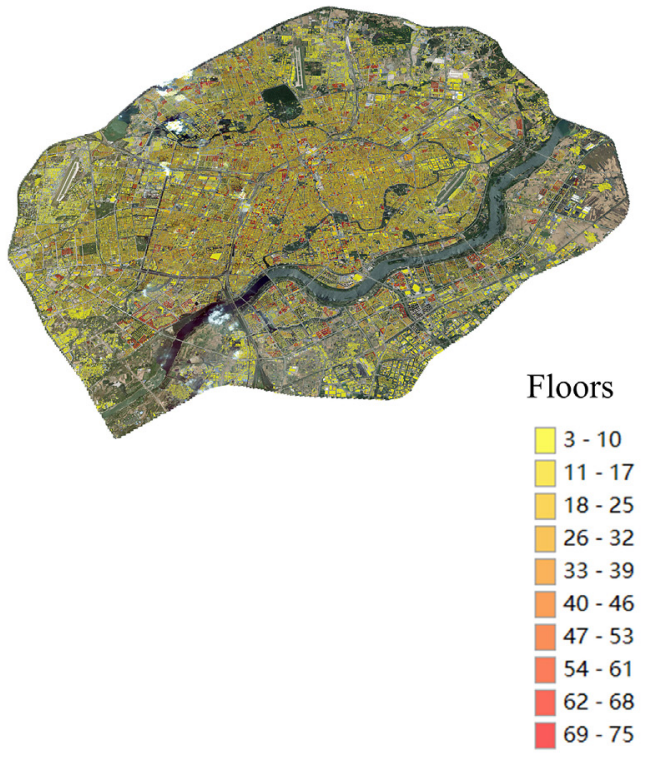

\section{d.DEM}

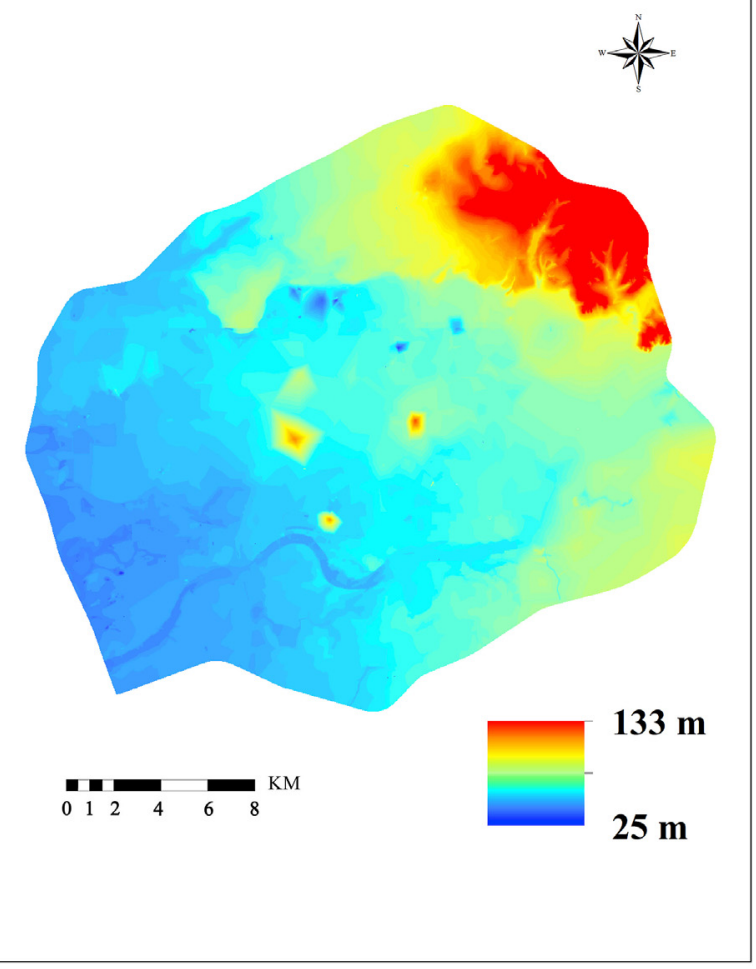

Fig. 1. Statistical data on socioeconomics (a); 3D building landscape (b); Land-use type (c) and digital elevation data (d) in Shenyang. 
Table 1

Descriptions of the variables used in SEM.

\begin{tabular}{|c|c|c|c|c|c|c|c|c|}
\hline Factor type & Variables & $\begin{array}{l}\text { Spatial } \\
\text { resolution }\end{array}$ & Data source & Unit & Mean & $\begin{array}{l}\text { Standard } \\
\text { Deviation }\end{array}$ & Max & Min \\
\hline \multirow[t]{4}{*}{ LST } & Spring LST & \multirow[t]{4}{*}{$1 \mathrm{~km}$} & \multirow[t]{4}{*}{ MODIS MOD11A2 data } & ${ }^{\circ} \mathrm{C}$ & 25.72 & 1.11 & 28.19 & 20.38 \\
\hline & Summer LST & & & ${ }^{\circ} \mathrm{C}$ & 35.64 & 1.61 & 38.20 & 31.42 \\
\hline & Autumn LST & & & ${ }^{\circ} \mathrm{C}$ & 20.32 & 0.85 & 21.89 & 17.79 \\
\hline & Winter LST & & & ${ }^{\circ} \mathrm{C}$ & 0.84 & 1.44 & 4.20 & -4.38 \\
\hline \multirow[t]{3}{*}{ Topography } & Elevation & \multirow[t]{3}{*}{$25 \mathrm{~m}$} & \multirow{3}{*}{$\begin{array}{l}\text { United States Geological Survey } \\
\text { (USGS) }\end{array}$} & $\mathrm{m}$ & 48.18 & 12.59 & 133 & 25 \\
\hline & Slope & & & $\circ$ & 0.45 & 0.98 & 17.63 & 0 \\
\hline & Relief amplitude & & & $\mathrm{m}$ & 1.09 & 2.11 & 29 & 0 \\
\hline \multirow[t]{5}{*}{ Land use types } & Distance from green space & \multirow[t]{5}{*}{$15 \mathrm{~m}$} & \multirow[t]{5}{*}{ Landsat imagery (USGS) } & $\mathrm{m}$ & 314.06 & 292.96 & 1710.26 & 0 \\
\hline & Distance from water body & & & $\mathrm{m}$ & 1251.94 & 1070.14 & 5800.05 & 0 \\
\hline & Distance from arable land & & & $\mathrm{m}$ & 1364.92 & 1516.03 & 6409.08 & 0 \\
\hline & Distance from residential land & & & $\mathrm{m}$ & 492.19 & 680.09 & 4399.01 & 0 \\
\hline & Landscape class & & & - & - & - & 8 & 0 \\
\hline \multirow[t]{2}{*}{ Socioeconomics } & $\begin{array}{l}\text { Regional population density in } \\
2017\end{array}$ & \multirow[t]{2}{*}{-} & \multirow[t]{2}{*}{ Shenyang Statistical Yearbook } & $\begin{array}{l}\text { person/ } \\
\mathrm{km}^{2}\end{array}$ & 6033.06 & 4891.5 & 12,360 & 362 \\
\hline & GDP Growth rate & & & $\%$ & 7.56 & 1.15 & 9.63 & 6.15 \\
\hline \multirow{2}{*}{$\begin{array}{l}\text { Building pattern (3D } \\
\text { data) }\end{array}$} & Average building height & \multirow[t]{2}{*}{$0.61 \mathrm{~m}$} & \multirow{2}{*}{$\begin{array}{l}\text { QuickBird imagery, Google Earth } \\
\text { imagery }\end{array}$} & \multirow[t]{2}{*}{$\mathrm{m}$} & 11.87 & 11.78 & 240 & 3 \\
\hline & Building shape coefficient & & & & 22.89 & 17.76 & 535 & 1 \\
\hline
\end{tabular}

GDP: gross domestic product.

www.r-project.org/). The VIF measures the increase in variance due to correlations among variables, so it is a measurement of the degree of collinearity for each variable (Craney and Surles, 2002). A VIF of 1 indicates no correlation, $1<\mathrm{VIF}<5$ indicates moderate correlation, and VIF $>5$ indicates high correlation (Shi et al., 2020a; Shi et al., 2020b). Factor selection was carried out by referring to VIF and combining with the ecological significance of variables. Twelve environmental factor variables were identified as meeting the requirements (Shi et al., 2020a, 2020b). The basic information of each variable is shown in Table 1 Finally, each factor layer was unified into the coordinate system of WGS84 on the ArcGIS platform, and the grid size was $25 \mathrm{~m}$.

\subsubsection{Topography}

Elevation and slope are the most common topographical factors. Relief amplitude refers to the elevation difference between the highest and lowest points within a certain distance range on the ground. This index is used to quantitatively describe the characteristics of surface configuration. The neighborhood statistical analysis function in ArcGIS was used here. The statistical area was calculated in a circular way, and the radius was set to 3 pixels. Descriptions of the variables such as spatial resolution, data source, maximum and minimum values are in Table 1.

\subsubsection{Land use types}

Land use type factors include distance from green space, water body, arable land and residential land, and landscape class (categorical variable), totally 5 variables. The land use type classification was verified with investigations in the field, showing an interpretation accuracy of $89 \%$. This is acceptable for use as a data source in our model. Then, the distance to four kinds of land use types and landscape class factors were analyzed to obtain the grid layers.

\subsubsection{Socioeconomics}

Growth rate refers to the average annual growth rate during the period 2011-2016. The "12th Five-year Plan" (2011-2015) of Shenyang Urban Planning developed by the Shenyang Municipal Committee redefined the boundary of the municipal district (the previous 11 districts were changed to 9 districts). In order to ensure a uniform data range and increase credibility, the socioeconomic indices for 2011-2016 were selected. Socioeconomic data of 9 districts were obtained from the Shenyang Statistical Yearbook.

\subsubsection{Building pattern}

Building height and building shape coefficient were used as three-dimensional (3D) landscape indicators. These data were extracted from high-resolution remote sensing images using building base profile extraction and building height inversion. Building base contour extraction was performed using an objectoriented method, and the base area of the building was calculated after image preprocessing, edge detection and linking, shadow and vegetation removal, binarization, region identification, feature measurement, region segmentation, and vectorization ( $\mathrm{Wu}$ et al., 2020).

Building height extraction was performed using a shadow length method, in which the shadow length of the highresolution Remote Sensing image of Shenyang in 2017 perpendicular to the building shadow was inverted to obtain the building height (Equation (1)) (Wu et al., 2020).

$A H=\frac{\sum_{j=1}^{n} H_{i j}}{n_{i}}$

where $A H$ is the average building height (architecture height) (m), $H_{i j}$ is the height of the $j$ th building in the $i$ th type, and $n_{i}$ is the number of buildings of the $i$ th type.

Finally, the building shape coefficient was calculated from the height, base area, and perimeter of the building. Building shape coefficient is the ratio of the building exterior surface in contact with the atmosphere to its enclosure volume (Equation (2)), and reflects the area dissipating energy and energy consumption. This is helpful for assessing the degree of thermal environment change due to building exhaust heat (Wu et al., 2020).

$B S C=\frac{P^{*} H+F}{F^{*} H}$

where $B S C$ is the building shape coefficient, $P$ is the building base perimeter, $H$ is the building height, and $F$ is the building base area. 


\subsection{Structural equation modeling (SEM) methods}

We used SEM to quantify the direct causal relationships between environmental factors and LST, as well as indirect relationships that were mediated by some environmental factors. We use SEM in this study for several reasons. (1) SEM can test the validity of an existing theoretical framework in a confirmatory manner (Byrne, 2013), so SEM is an adequate tool to validate and/or invalidate our hypothesized model. In our study, we assumed that topography, land use types, socioeconomics factors and building pattern would have effects on LST and they would interaction with each other, which is consistent with previous findings (Chen et al., 2021). They used Landsat-8 OLI/TIRS data to examine the relationship of DEM, index-based built-up index (IBI), modified normalized difference water index (MNDWI), normalized difference vegetation index (NDVI), population, and Gross Domestic Product (GDP) with LST in Wuhan, China. The relations of MNDWI, IBI, and NDVI to the distribution of water areas, built-up, and green spaces and their interactions were the main factors affecting LST. The study also shows that the driving factors of LST pattern in Wuhan are complex and seasonal, not static (Huang et al., 2019), because the most powerful explanatory factors are different in each season. Cui et al. (2016) also indicated the influence of socioeconomics factors on LST. The surface urban heat island intensity, GDP, and population were correlated to each other (Cui et al., 2016). (2) SEM can evaluate the complex, real-world relationships among multiple variables beyond the traditional multiple regression approach (Colman and Schimel, 2013). The SEM can examine the causal relationships among multiple variables, as well as how those variables interact with each other to produce the overall effect, which provides illustrations and insights on the mechanisms of how environmental factors affect LST. (3) SEM can quantify these causal relationships in a standardized manner such that different metrics can be compared across variables (Moustaki et al., 2004; Kelloway, 1996; Cliff, 1983). The variables in our study are in various units, making it difficult to compare the relative effects of one variable on another. The standardized total effects generated by SEM are comparable across all types of variables.

To assess the significance and magnitude of how environmental factors affected LST, SEM was conducted in AMOS 26 (IBM Corporation, Meadville, PA, USA). First, we proposed an a priori model defining expected relationships between LST and the 12 environmental factors according to background knowledge and scientific hypotheses. Second, we tested if important pathways were left out (modification indices $\geq 4$ ) and if the existing pathways were significant $(p \leq 0.05)$. Third, we revised the a priori model by adding missing pathways and dropping insignificant pathways based on model fit metrics and expert judgement. All data were logtransformed, and Mahalanobis distances were calculated to determine and remove outliers to achieve multivariate normality (kurtosis value $\leq 7$ ). The final dataset comprised of 525 samples (i.e. $98.7 \%$ of the original dataset).

Path coefficients were tested with maximum likelihood estimation at $p<0.001$ and are reported as standardized path coefficients in standard deviation units. Standardized path coefficients represent the magnitude of the effect of each individual independent variable (i.e. environmental factor) on the dependent variable (i.e. LST). The higher the absolute value of the standardized path coefficient, the stronger the effect. Model fit was evaluated by (1) the minimum discrepancy divided by its degrees of freedom (CMIN/DF) in the range of 1-3 (Carmines and McIver, 1983), (2) the goodness of fit index (GFI) close to 1 (Tanaka and Huba, 1985), (3) the comparative fit index (CFI) close to 1 (Bentler, 1990), and (4) the root mean square error of approximation (RMSEA) less than 0.05 (Browne and Cudeck, 1993). Full details on development and modification of a structural equation model are in Li et al. (2019).

\section{Results}

\subsection{Model fit and standardized total effects}

The goodness-of-fit indices indicated that our data were optimally fit to the SEM $(\mathrm{CMIN} / \mathrm{DF}=2.04, \mathrm{GFI}=0.97, \mathrm{CFI}=0.98$, RMSEA $=0.04$, Fig. 2$)$. All the estimated parameters were positive and significant $(p \leq 0.001)$. The model explained $40 \%, 45 \%, 34 \%$, and $37 \%$ of the variations in the spring, summer, autumn, and winter LSTs, respectively. These pathways led to the standardized total effects in Table 2. Overall, topography, land-use type, and socioeconomics all had direct and/or indirect effects on LST but building pattern did not affect LST.

The most critical factors affecting LST varied with season: distance from arable land during summer and autumn, and elevation during winter. In spring, LST was directly affected by elevation, relief amplitude, distance from green space, distance from the nearest water body, and GDP growth rate. For instance, elevation had a direct negative effect on spring LST (path coefficient $=-0.16$ ), indicating that 1.00 unit of increase in elevation $(\mathrm{m})$ will cause a 0.16 -unit decrease in spring LST $\left({ }^{\circ} \mathrm{C}\right)$. Elevation and slope also had indirect effects on spring LST through other factors. The distance from a water body had the largest effect on spring LST (total effect $=0.51$ ). In winter, elevation, slope, and population density were the most influential factors, with respective path coefficients of $-0.5,-0.41$, and 0.29 .

\subsection{Potential influences on seasonal variations}

The topographic factors of slope and relief amplitude had direct negative impacts on LST. The path coefficients of relief amplitude on spring and winter LST were -0.14 and -0.18 , and those of slope on spring, summer, fall, and winter LST were $-0.09,-0.12,-0.13$, and -0.41 , respectively (Table 2 ). The path coefficients of elevation for the four seasonal LSTs were $0.03,-0.02,-0.23$, and -0.50 , respectively (Table 2). In terms of land use, distance from arable land and distance from green space were positively correlated with LST. Specifically, the path coefficients for the distance from arable land on summer, fall, and winter LST were $0.47,0.42$, and 0.26 , and those of the distance from green space for spring, summer, and fall LST were $0.19,0.21$, and 0.19 , respectively. In contrast, the distance from residential areas was negatively correlated with summer LST, with a coefficient of -0.11 . Distance from a water body was positively correlated with LST, especially in spring and summer, with coefficients of 0.51 and 0.42 , respectively. Among the socioeconomic factors, population density had a positive impact on LST, and the path coefficients of summer, fall, and winter LST were 0.10, 0.21, and 0.29 , respectively.

In terms of indirect impact, the slope indirectly influenced LST by affecting elevation and relief amplitude. Elevation affected LST by affecting the average gross domestic product (GDP) growth rate. The effect of distance from each landscape type (such as green space and arable land) on LST changes with the change of landscape type factor. The distance from arable land affected LST through its impact on population density.

\section{Discussion}

\subsection{Temporal and spatial differences of LST}

The study area has four distinct seasons: spring LST is 20.4-28.2 ${ }^{\circ} \mathrm{C}$, summer LST is $31.4-38.2{ }^{\circ} \mathrm{C}$, autumn LST is 


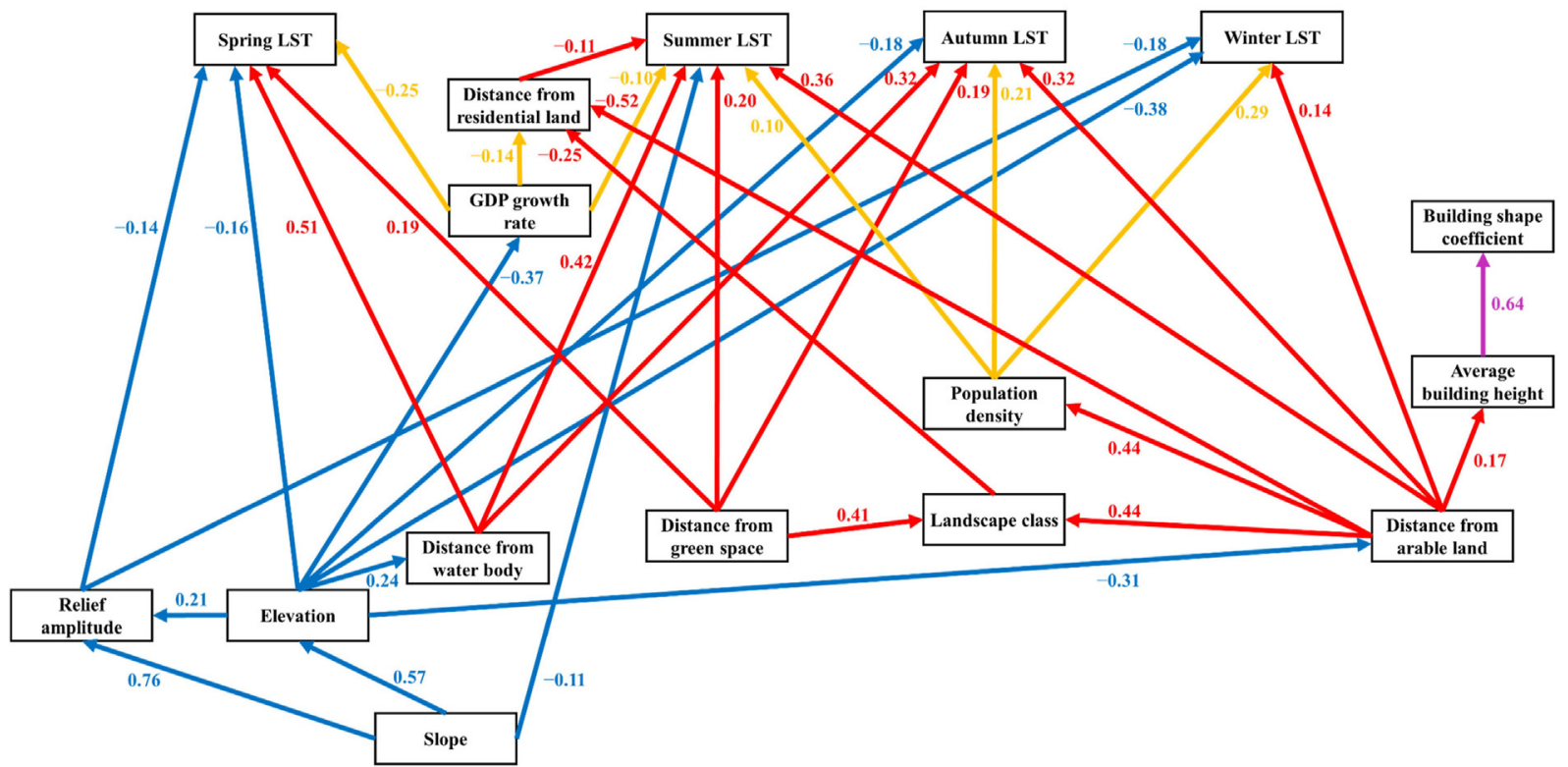

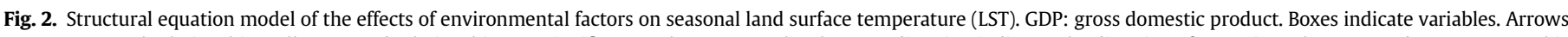

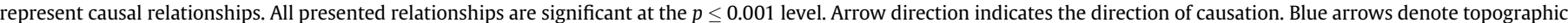

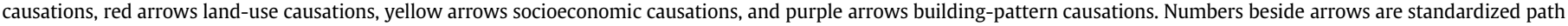
coefficients, i.e., effect sizes. See Table 2 for standardized total effects.

Table 2

Standardized total effects of environmental factors on seasonal land surface temperature (LST).

\begin{tabular}{|c|c|c|c|c|c|c|c|c|c|c|c|}
\hline & Elevation & Slope & $\begin{array}{l}\text { Relief } \\
\text { amplitude }\end{array}$ & $\begin{array}{l}\text { Distance from } \\
\text { green space }\end{array}$ & $\begin{array}{l}\text { Distance from } \\
\text { water body }\end{array}$ & $\begin{array}{l}\text { Distance from } \\
\text { arable land }\end{array}$ & $\begin{array}{l}\text { Distance from } \\
\text { residential land }\end{array}$ & $\begin{array}{l}\text { Landscape } \\
\text { class }\end{array}$ & $\begin{array}{l}\text { Population } \\
\text { density }\end{array}$ & $\begin{array}{l}\text { GDP } \\
\text { growth } \\
\text { rate }\end{array}$ & $\begin{array}{l}\text { Average } \\
\text { building } \\
\text { height }\end{array}$ \\
\hline Spring LST & 0.03 & -0.09 & -0.14 & 0.19 & 0.51 & 0.00 & 0.00 & 0.00 & 0.00 & -0.25 & 0.00 \\
\hline Summer LST & -0.02 & -0.12 & 0.00 & 0.21 & 0.42 & 0.47 & -0.11 & 0.03 & 0.10 & -0.09 & 0.00 \\
\hline Autumn LST & -0.23 & -0.13 & 0.00 & 0.19 & 0.32 & 0.42 & 0.00 & 0.00 & 0.21 & 0.00 & 0.00 \\
\hline Winter LST & -0.50 & -0.41 & -0.18 & 0.00 & 0.00 & 0.26 & 0.00 & 0.00 & 0.29 & 0.00 & 0.00 \\
\hline Elevation & - & 0.57 & 0.00 & 0.00 & 0.00 & 0.00 & 0.00 & 0.00 & 0.00 & 0.00 & 0.00 \\
\hline Slope & 0.00 & - & 0.00 & 0.00 & 0.00 & 0.00 & 0.00 & 0.00 & 0.00 & 0.00 & 0.00 \\
\hline Relief amplitude & 0.21 & 0.89 & - & 0.00 & 0.00 & 0.00 & 0.00 & 0.00 & 0.00 & 0.00 & 0.00 \\
\hline $\begin{array}{l}\text { Distance from } \\
\text { green space }\end{array}$ & 0.00 & 0.00 & 0.00 & - & 0.00 & 0.00 & 0.00 & 0.00 & 0.00 & 0.00 & 0.00 \\
\hline $\begin{array}{r}\text { Distance from } \\
\text { water body }\end{array}$ & 0.24 & 0.18 & 0.00 & 0.00 & - & 0.00 & 0.00 & 0.00 & 0.00 & 0.00 & 0.00 \\
\hline $\begin{array}{l}\text { Distance from } \\
\text { arable land }\end{array}$ & -0.31 & -0.18 & 0.00 & 0.00 & 0.00 & - & 0.00 & 0.00 & 0.00 & 0.00 & 0.00 \\
\hline $\begin{array}{l}\text { Distance from } \\
\text { residential land }\end{array}$ & 0.25 & 0.14 & 0.00 & -0.10 & 0.00 & -0.63 & - & -0.25 & 0.00 & -0.14 & 0.00 \\
\hline Landscape class & -0.14 & -0.08 & 0.00 & 0.41 & 0.00 & 0.44 & 0.00 & - & 0.00 & 0.00 & 0.00 \\
\hline $\begin{array}{l}\text { Population } \\
\text { density }\end{array}$ & -0.14 & -0.08 & 0.00 & 0.00 & 0.00 & 0.44 & 0.00 & 0.00 & - & 0.00 & 0.00 \\
\hline GDP growth rate & -0.37 & -0.21 & 0.00 & 0.00 & 0.00 & 0.00 & 0.00 & 0.00 & 0.00 & - & 0.00 \\
\hline $\begin{array}{l}\text { Average building } \\
\text { height }\end{array}$ & -0.05 & -0.03 & 0.00 & 0.00 & 0.00 & 0.17 & 0.00 & 0.00 & 0.00 & 0.00 & - \\
\hline $\begin{array}{l}\text { Building shape } \\
\text { coefficient }\end{array}$ & -0.03 & -0.02 & 0.00 & 0.00 & 0.00 & 0.11 & 0.00 & 0.00 & 0.00 & 0.00 & 0.64 \\
\hline
\end{tabular}

GDP: gross domestic product. All effects are significant at $p<0.001$ level. See Fig. 1 for direct and indirect pathways.

$17.8-21.9^{\circ} \mathrm{C}$, and winter LST is $-4.4-4.2^{\circ} \mathrm{C}$. The thermal center is located in the central urban area. The central urban area is densely populated, with a large amount of energy consumption and a relatively high motor vehicle flow. The land use mainly consists of construction land and hardened road surfaces, including large amounts of concrete and asphalt pavement, masonry structures, and other building materials. The urban underlying surface has high thermal conductivity, high heat capacity, and low vegetation coverage. Compared with the natural underlying surface, the evaporation of heat is reduced, and the heat storage increases, which is the main causes of heat in the city. The areas with relatively low temperatures are mainly areas with high vegetation coverage, such as agricultural land and forestland, as well as some water bodies. Similar results were obtained in case studies of Beijing and Shenyang (Zhang et al., 2014; Guo et al., 2017).

\subsection{Effects of environmental factors on LST}

In terms of topographic factors, elevation and slope had negative effects on LST. In Shenyang, large slopes, relief amplitude, and 
vegetation coverage are usually in suburban areas, while the interannual temperature is relatively low in suburbs, especially in the hills of the Northeast. The reason is that urban building materials, mainly asphalt and concrete, have a low albedo and high thermal inertia, resulting in increased net solar radiation entering the urban system (Rizwan et al., 2008). Decreases in areas of vegetation and water surface will result in a decrease in latent heat flux in the output component of the surface energy balance (Zhang et al., 2014). In addition, a large amount of anthropogenic heat from buildings, transportation, and industrial production is released into the atmosphere (Benz et al., 2015; Salamanca et al., 2014). This can contribute to the proportion of sensible heat flux out of the total energy output, forming a heat island effect. In terms of the social economy, the population density had a positive effect on LST. The higher the population density is, the closer to the urban center a location is, and the heat island effect is more obvious, which causes the temperature to rise. However, the GDP growth rate had a negative effect on LST. This could be explained by the fact that GDP growth comes at the expense of many natural habitats, and these areas are beneficial for lower surface temperatures (Du et al., 2020; Shen and Xu, 2020; Jia and Zhao, 2019).

Hu et al. (2020) showed that the 2D land-use variables were most strongly correlated with LST in summer and spring, but 3D building-related variables had stronger impacts in colder weather. The sky view factor, a 3D measure of urban morphology, also had strong impacts in summer and winter (Hu et al., 2020). The two building pattern factors (average building height and building shape coefficient) selected in this study had no significant effect on the LST, which might be due to the selection of specific indicators. These two indicators focus on the three-dimensional characteristics of the building, while the real effect on the LST might come from other characteristics of the building, for example, the building coverage ratio, projected area of buildings, etc. This has been confirmed by Yang et al. (2018), who showed that surface temperature was weakly correlated with building height but moderately correlated with building density. In contrast, Sun et al. (2020) showed that indices of building landscape pattern had a significant impact on the LST in a block scale study. Alavipanah et al. (2018) found that the 3D indices had a stronger effect on the LST than the 2D indices on the block scale. Overall, it seems that both 2D and 3D indices affect LST (Alavipanah et al., 2018; Liu et al., 2020), but there is still no consensus on the effects of specific indicators (Yang et al., 2018; Zheng et al., 2019). The underlying mechanism is influenced by season, urban morphology, and configuration of green space (Berger et al., 2017; Guo et al., 2019; Yu et al., 2020).

\subsection{Interaction effects of environmental factors and season on LST}

It is worth mentioning that the distance from green space and water bodies had positive effects on spring, summer, and fall LST, however, it had no significant effect on the winter LST (Table 2). The specific heat capacity of water is higher than that of soil, which has a regulating effect on temperature. Previous studies (Peng et al., 2018; Wang and Murayama, 2020) have confirmed that water and vegetation play an important role in mitigating surface UHI. Chen et al. (2021) showed that the maximum temperature difference between land covers occurs in spring and summer, while this difference can be ignored in winter. This is consistent with the conclusion of our study. In our study, in spring and summer, there are kayaks and sightseeing cruises in Hun River, and people who have picnics, barbeques, cycling, walking and other activities on the shore. Since the winter temperatures in Shenyang are almost always below freezing, there is no water transport in Hun River and the green space on both banks disappeared. So anthropogenic thermal emissions are associated with reduced transport heat release in winter. These are the possible reasons why the cooling effect is not significant in winter.

By comparing the major influencing factors of the variables in this study (Table 2), we found that in spring, the distance from water body had the largest effect on LST; in summer and fall, the distance from bare land had the largest impact on LST, followed by the distance from water body; in winter, elevation, slope, and population density had relatively large impacts on LST. Water body and green areas are important land-use types that regulate the climate and the environment and have a significant impact on LST in spring, summer, and fall. In the winter in winter cities, vegetation is dormant, water bodies are frozen, and the major environmental factors affecting LST become topographic and population density factors. In addition, winter heating sources and heat emission are different from those in other seasons, which causes the factors influencing LST in winter to be different from those in other seasons.

The above characteristics have also been confirmed in the study of other heat islands in winter cities (Geletic et al., 2019; Khorrami and Gunduz, 2020). For example, in northern West Siberian cities, the LST analysis by Miles and Esau (2017) found differences between summer and winter regarding the UHI effect, supporting the hypothesis of seasonal differences in the causes of UHIs (Miles and Esau, 2017). In summertime, with long daytime, the UHI intensity is mainly determined by surface albedo, reduced evaporation, and the amount of incoming solar radiation. In wintertime, with low temperature and small amount of solar radiation, the UHI intensity is determined by anthropogenic heat pollution. This is consistent with our research hypothesis. Moreover, Yang et al. (2020) indicated that the spatial pattern of LST had dramatic monthly and seasonal changes in a snow-climate city, and the effects of driving factors also had seasonal variations. Almost half of the area was covered with snow (43.48\%) in winter. In winter, the effect of vegetation on LST is not obvious (Yang et al., 2020b). This is consistent with our findings.

\subsection{Research prospects}

This study selected 12 common environmental factors describing the environmental characteristics of built areas. The selected variables explained $34-45 \%$ of the changes in urban LST in each season. In addition to the 12 factors, factors such as meteorology, transportation, industrial emissions, and heating methods have been shown to impact the spatial distribution of surface heat radiation (Benz et al., 2015; Chen et al., 2016; Huang and Cadenasso, 2016; Salamanca et al., 2014; Wang et al., 2014), which should be introduced into future research. Here, spatially uniform sampling was used in this study to obtain an ideal result. However, further methodological studies are required to evaluate how this and other sampling strategies (i.e. spatially uniform sampling, stratified sampling, random sampling, the number of sampling points) affect model performance and reliability (Bentler and Yuan, 1999).

\section{Conclusions}

In the context of rapid urbanization, the dominant factors affecting LST and the strengths of their impacts are different in different seasons, though the dominant factors are interrelated. The SEM can well explain the seasonal variation in urban LST in winter regions. The results show that the land-use factors, such as distance from water bodies and distance from green space, have a positive effect on LST, and this effect is more significant in the spring and summer. Optimizing the landscape pattern of green space and water bodies is essential to reduce LST. This is particularly important during this time of year when energy consumption for cooling 
is at its highest. In autumn and winter, the influence of topographic factors is significantly enhanced, and greater elevation and slope will result in a lower LST. Of the social and economic factors, lowering population density can achieve the purpose of cooling. Planners and decision-makers can establish satellite cities and adopt other strategies to improve the urban thermal environment by decentralizing urban functions.

This study shows that the influence of the 2D indices on the LST variation is more important than that of the $3 \mathrm{D}$ indices. This effect is related to seasonal variations, selection of characteristic indicators, urban morphology and compactness, and configuration of green space and street trees. Of course, when focusing on seasonal variations, it is equally important to consider the synergistic management of multiseasonal LST improvements that pay attention to seasonal variations. This requires planners and managers to take comprehensive measures to mitigate the UHI effect by targeting dominant factors such as the layout of water bodies and green spaces and the population density.

\section{Credit author statement}

Conceptualization and Methodology: Lidong Li. Investigation: Chunlin Li, Wen Wu. Data curation and formal analysis: Wen Wu, Lidong Li. Writing - Original Draft: Wen Wu. Writing - Review \& Editing: Lidong Li, Chunlin Li. Funding acquisition: Chunlin Li. All authors read and approved the final manuscript.

\section{Declaration of competing interest}

The authors declare that they have no known competing financial interests or personal relationships that could have appeared to influence the work reported in this paper.

\section{Acknowledgements}

Funding for this project was provided by the National Natural Science Foundation of China (Nos. 41871162 and 41871192) and the Fundamental Research Funds for the Central Universities of China (No. N2011005). We thank Dr. Virginia Jin for the help in polishing this manuscript. We thank the anonymous reviewers for their constructive comments and their efforts in improving the quality of this manuscript.

\section{References}

Alavipanah, S., Schreyer, J., Haase, D., Lakes, T., Qureshi, S., 2018. The effect of multidimensional indicators on urban thermal conditions. J. Clean. Prod. 177, 115-123. https://doi.org/10.1016/j.jclepro.2017.12.187.

Bentler, P.M., 1990. Comparative fit indexes in structural models. Psychol. Bull. 107 (2), 238. https://doi.org/10.1037/0033-2909.107.2.238.

Bentler, P.M., Yuan, K.H., 1999. Structural equation modeling with small samples: test statistics. Multivariate Behav. Res. 34 (2), 181-197. https://doi.org/10.1207/ S15327906Mb340203.

Benz, S.A., Bayer, P., Menberg, K., Jung, S., Blum, P., 2015. Spatial resolution of anthropogenic heat fluxes into urban aquifers. Sci. Total Environ. 524, 427-439. https://doi.org/10.1016/j.scitotenv.2015.04.003.

Berger, C., Rosentreter, J., Voltersen, M., Baumgart, C., Schmullius, C., Hese, S., 2017. Spatio-temporal analysis of the relationship between 2D/3D urban site characteristics and land surface temperature. Remote Sens. Environ. 193, 225-243. https://doi.org/10.1016/j.rse.2017.02.020.

Browne, M.W. Cudeck, R. 1993. Alternative ways of assessing model fit. In: Bollen, K.A., Long, J.S. (Eds.), Testing Structural Equation Models. Sage, Beverly Hills, CA, pp. 111-135.

Byrne, B.M., 2013. Structural Equation Modeling with AMOS: Basic Concepts, Applications, and Programming, second ed. Routledge, New York.

Carmines, E.G., McIver, J.P., 1983. An introduction to the analysis of models with unobserved variables. Polit. Method 51-102.

Chen, A.L., Sun, R.H., Chen, L.D., 2012. Applicability of traditional landscape metrics in evaluating urban heat island effect. Chin. J. Appl. Ecol. 23, 2077-2086. https://doi.org/10.13287/j.1001-9332.2012.0321, 08.

Chen, Y., Schleicher, N., Fricker, M., Cen, K., Liu, X.-l., Kaminski, U., Yu, Y., Wu, X.-f.,
Norra, S., 2016. Long-term variation of black carbon and $\mathrm{PM}_{2.5}$ in Beijing, China with respect to meteorological conditions and governmental measures. Environ. Pollut. 212, 269-278. https://doi.org/10.1016/j.envpol.2016.01.008.

Chen, L., Wang, X.L., Cai, X.B., Yang, C., Lu, X.R., 2021. Seasonal variations of daytime land surface temperature and their underlying drivers over Wuhan, China. Rem. Sens. 13, 323. https://doi.org/10.3390/rs13020323.

Cliff, N., 1983. Some cautions concerning the application of causal modeling methods. Multivariate Behav. Res. 18 (1), 115-126. https://doi.org/10.1207/ s15327906mbr1801 7.

Colman, B.P., Schimel, J.P., 2013. Drivers of microbial respiration and net $\mathrm{N}$ mineralization at the continental scale. Soil Biol. Biochem. 60, 65-76. https://doi:10. 1016/j.soilbio.2013.01.003.

Craney, T.A., Surles, J.G., 2002. Model-dependent variance inflation factor cutoff values. Qual. Eng. 14 (3), 391-403. https://doi:10.1081/QEN-120001878.

Cui, Y.P., Xu, X.L., Dong, J.W., Qin, Y.C., 2016. Influence of urbanization factors on surface urban heat island intensity: a comparison of countries at different developmental phases. Sustainability 8, 706. https://doi:10.3390/su8080706.

Du, H., Song, X., Jiang, H., Kan, Z., Wang, Z., Cai, Y., 2016. Research on the cooling island effects of water body: a case study of Shanghai, China. Ecol. Indicat. 67, 31-38. https://doi.org/10.1016/j.ecolind.2016.02.040.

Du, J., Xiang, X.Y., Zhao, B.Y., Zhou, H.H., 2020. Impact of urban expansion on land surface temperature in Fuzhou, China using Landsat imagery. Sustain. Cities Soc. 61, 102346. https://doi.org/10.1016/j.scs.2020.102346.

Geletic, J., Lehnert, M., Savic, S., Milosevic, D., 2019. Inter-/intra-zonal seasonal variability of the surface urban heat island based on local climate zones in three central European cities. Build. Environ. 156, 21-32. https://doi.org/10.1016/ j.buildenv.2019.04.011.

Guo, G.H., Wu, Z.F., Liu, X.N., 2015. Seasonal variations of urban heat environment and its relationship to impervious surface: a case study of Guangzhou core urban area. Chin. Ecol. Environ. Sci. 24 (2), 270-277. https://doi.org/10.16258/ j.cnki.1674-5906.2015.02.014.

Guo, J.T., Hu, Y.M., Xiong, Z.P., Bu, R.C., Yan, X.L., Liu, M., 2017. Spatiotemporal variations characteristics of summer heat island effect in Shenyang over the past 15 years. Chin. Environ. Sci. Technol. 40 (S2), 293-299. https://doi.org/10.3969/ j.issn.1003-6504.2017.S2.055.

Guo, G.H., Wu, Z.F., Chen, Y.B., 2019. Complex mechanisms linking land surface temperature to greenspace spatial patterns: evidence from four southeastern Chinese cities. Sci. Total Environ. 674, 77-87. https://doi.org/10.1016/ j.scitotenv.2019.03.402.

Holben, B.N., 1986. Characteristics of maximum-value composite images from temporal AVHRR data. Int. J. Rem. Sens. 7 (11), 1417-1434. https://doi.org/ $10.1080 / 01431168608948945$.

Hu, D.Y., 2019. Urban Remote Sensing: Elements, Morphology and Functions. Science Press, Beijing.

Hu, Y.F., Dai, Z.X., Guldmann, J.M., 2020. Modeling the impact of 2D/3D urban indicators on the urban heat island over different seasons: a boosted regression tree approach. J. Environ. Manag. 266, 110424. https://doi.org/10.1016/ j.jenvman.2020.110424.

Huang, G., Cadenasso, M.L., 2016. People, landscape, and urban heat island: dynamics among neighborhood social conditions, land cover and surface temperatures. Landsc. Ecol. 31 (10), 2507-2515. https://doi.org/10.1007/s10980016-0437-z.

Huang, X., Wang, Y., 2019. Investigating the effects of 3D urban morphology on the surface urban heat island effect in urban functional zones by using highresolution remote sensing data: a case study of Wuhan, Central China. Isprs J. Photogramm. 152, 119-131. https://doi.org/10.1016/j.isprsjprs.2019.04.010.

Huang, Q., Huang, J., Yang, X., Fang, C., Liang, Y., 2019. Quantifying the seasonal contribution of coupling urban land use types on urban heat island using land contribution index: a case study in Wuhan, China. Sustain. Cities Soc. 44 666-675. https://doi.org/10.1016/j.scs.2018.10.016.

Jia, W.X., Zhao, S.Q., 2019. Trends and drivers of land surface temperature along the urban-rural gradients in the largest urban agglomeration of China. Sci. Total Environ. 711, 134579. https://doi.org/10.1016/j.scitotenv.2019.134579.

Jiang, S.D., Zhan, W.F., Yang, J., Liu, Z.H., Huang, F., Lai, J.M., Li, J.F., Hong, F.L., Huang, Y., Chen, J.K., Lee, X.H., 2020. Urban heat island studies based on local climate zones: a systematic overview. Chin. Acta Geogr. Sin. 75 (9), 1860-1878. https://doi.org/10.11821/dlxb202009004.

Kelloway, E.K., 1996. Common practices in structural equation modeling. Int. Rev. Ind. Organ. Psychol. 10 (11), 141-180.

Khorrami, B., Gunduz, O., 2020. Spatio-temporal interactions of surface urban heat island and its spectral indicators: a case study from Istanbul metropolitan area, Turkey. Environ. Monit. Assess. 192 (6) https://doi.org/10.1007/s10661-02008322-1.

Kuang, W., Dou, Y., Zhang, C., Chi, W., Liu, A., Liu, Y., Zhang, R., Liu, J., 2015. Quantifying the heat flux regulation of metropolitan land use/land cover components by coupling remote sensing modeling with in situ measurement. J. Geophys. Res. Atmos. 120 (1), 113-130. https://doi.org/10.1002/ 2014JD022249.

Li, L., Wilson, C.B., He, H., Zhang, X., Zhou, F., Schaeffer, S.M., 2019. Physical, biochemical, and microbial controls on amino sugar accumulation in soils under long-term cover cropping and no-tillage farming. Soil Biol. Biochem. 135, 369-378. https://doi.org/10.1016/j.soilbio.2019.05.017.

Liu, Y., Chen, C., Li, J., Chen, W.-Q., 2020. Characterizing three dimensional (3-D) morphology of residential buildings by landscape metrics. Landsc. Ecol. 35, 2587-2599. https://doi.org/10.1007/s10980-020-01084-8. 
Luan, Q., Jiang, W., Liu, S., Guo, H., 2020. Impact of urban 3D morphology on particulate matter $2.5\left(\mathrm{PM}_{2.5}\right)$ concentrations: case study of Beijing, China. Chin. Geogr. Sci. 30 (2), 294-308. https://doi.org/10.1007/s11769-020-1112-5.

Meehl, G.A., Tebaldi, C., 2004. More intense, more frequent, and longer lasting heat waves in the 21st century. Science 305 (5686), 994-997. https://doi.org/ $10.1126 /$ science.1098704.

Miles, V., Esau, I., 2017. Seasonal and spatial characteristics of urban heat islands (UHIs) in Northern West Siberian cities. Rem. Sens. 9 (10), 989. https://doi.org/ $10.3390 /$ rs9100989.

Moustaki, I., Joreskog, K.G., Mavridis, D., 2004. Factor models for ordinal variables with covariate effects on the manifest and latent variables: a comparison of LISREL and IRT approaches. Struct. Equ. Model. 11 (4), 487-513. https://doi.org/ 10.1207/s15328007sem1104_1.

Peng, J., Jia, J.L., Liu, Y.X., Li, H.L., Wu, J.S., 2018. Seasonal contrast of the dominant factors for spatial distribution of land surface temperature in urban areas. Remote Sens. Environ. 215, 255-267. https://doi.org/10.1016/j.rse.2018.06.010.

Peng, J., Qiao, R.L., Liu, Y.X., Blaschke, T., Li, S.C., Wu, J.S., Xu, Z.H., Liu, Q.Y., 2020. A wavelet coherence approach to prioritizing influencing factors of land surface temperature and associated research scales. Remote Sens. Environ. 246, 111866. https://doi.org/10.1016/j.rse.2020.111866.

Rizwan, A.M., Dennis, Y.C.L., Liu, C., 2008. A review on the generation, determination and mitigation of Urban Heat Island. J. Environ. Sci. 20 (1), 120-128. https://doi.org/10.1016/S1001-0742(08)60019-4.

Salamanca, F., Georgescu, M., Mahalov, A., Moustaoui, M., Wang, M., 2014. Anthropogenic heating of the urban environment due to air conditioning. J. Geophys. Res. Atmos. 119 (10), 5949-5965. https://doi.org/10.1002/ 2013JD021225.

Shen, Z.C., Xu, X.L., 2020. Influence of the economic efficiency of built-up land (EEBL) on urban heat islands (UHIs) in the Yangtze river delta urban agglomeration (YRDUA). Rem. Sens. 12 (23), 3944. https://doi.org/10.3390/rs12233944.

Shi, T., Dirienzo, N., Requia, W.J., Hatzopoulou, M., Adams, M.D., 2020a. Neighbourhood scale nitrogen dioxide land use regression modelling with regression kriging in an urban transportation corridor. Atmos. Environ. 223, 117218. https://doi.org/10.1016/j.atmosenv.2019.117218.

Shi, T., Hu, Y., Liu, M., Li, C., Zhang, C., Liu, C., 2020b. Land use regression modelling of $\mathrm{PM}_{2.5}$ spatial variations in different seasons in urban areas. Sci. Total Environ. 743, 140744. https://doi.org/10.1016/j.scitotenv.2020.140744.

Sun, F., Liu, M., Wang, Y., Wang, H., Che, Y., 2020. The effects of 3D architectural patterns on the urban surface temperature at a neighborhood scale: relative contributions and marginal effects. J. Clean. Prod. 258, 120706. https://doi.org/ 10.1016/j.jclepro.2020.120706.

Tanaka, J.S., Huba, G.J., 1985. A fit index for covariance structure models under arbitrary GLS estimation. Br. J. Math. Stat. Psychol. 38 (2), 197-201. https:// doi.org/10.1111/j.2044-8317.1985.tb00834.x.

Tian, Y., Zhou, W., Qian, Y., Zheng, Z., Yan, J., 2019. The effect of urban 2D and 3D morphology on air temperature in residential neighborhoods. Landsc. Ecol. 34 (5), 1161-1178. https://doi.org/10.1007/s10980-019-00834-7.

Wang, R., Murayama, Y., 2020. Geo-simulation of land use/cover scenarios and impacts on land surface temperature in Sapporo, Japan. Sustain. Cities Soc. 63 , 102432. https://doi.org/10.1016/j.scs.2020.102432.

Wang, L., Zhang, N., Liu, Z., Sun, Y., Ji, D., Wang, Y., 2014. The influence of climate factors, meteorological conditions, and boundary-layer structure on severe haze pollution in the Beijing-Tianjin-Hebei region during January 2013. Adv. Meteorol. (7), 1-14. https://doi.org/10.1155/2014/685971.

White, R., Uljee, I., Engelen, G., 2012. Integrated modelling of population, employment and land-use change with a multiple activity-based variable grid cellular automaton. Int. J. Geogr. Inf. Sci. 26 (7), 1251-1280. https://doi.org/10.1080/ 13658816.2011.635146.

Wu, W., Li, C., Liu, M., Hu, Y., Xiu, C., 2020. Change of impervious surface area and its impacts on urban landscape: an example of Shenyang between 2010 and 2017 Ecosys. Health Sustain. 6 (1), 1767511. https://doi.org/10.1080/ 20964129.2020.1767511.

Yang, J., Su, J., Xia, J., Jin, C., Li, X., Ge, Q., 2018. The impact of spatial form of urban architecture on the urban thermal environment: a case study of the Zhongshan District, Dalian, China. IEEE J. STARS 11 (8), 2709-2716. https://doi.org/10.1109/ JSTARS.2018.2808469.

Yang, J.W.Y.C., Xiu, C.L., Xiao, X.M., Jin, C., 2020a. Optimizing local climate zones to mitigate urban heat island effect in human settlements. J. Clean. Prod. 275, 123767. https://doi.org/10.1016/j.jclepro.2020.123767.

Yang, C., Yan, F., Lei, X., Ding, X., Zheng, Y., Liu, L., Zhang, S., 2020b. Investigating seasonal effects of dominant driving factors on urban land surface temperature in a snow-climate city in China. Rem. Sens. 12 (18), 3006. https://doi.org/ $10.3390 /$ rs 12183006.

Yao, Y., Chen, X., Qian, J., 2018. Research progress on the thermal environment of the urban surfaces. Chin. Acta Ecol. Sin. 38 (3), 1134-1147. https://doi.org/10.5846/ stxb201611022233.

Yu, Z., Chen, S., Wong, N.H., Ignatius, M., Deng, J., He, Y., Hii, D.J.C., 2020. Dependence between urban morphology and outdoor air temperature: a tropical campus study using random forests algorithm. Sustain. Cities Soc. 61, 102200. https://doi.org/10.1016/j.scs.2020.102200.

Zeng, L.L., Wardlow, B.D., Tadesse, T., Shan, J., Hayes, M.J., Li, D.R., Xiang, D.X., 2015. Estimation of daily air temperature based on MODIS land surface temperature products over the Corn Belt in the US. Rem. Sens. 7 (1), 951-970. https:// doi.org/10.3390/rs70100951.

Zhang, B., Xie, G.-d., Gao, J--X., Yang, Y., 2014. The cooling effect of urban green spaces as a contribution to energy-saving and emission-reduction: a case study in Beijing, China. Build. Environ. Times 76, 37-43. https://doi.org/10.1016/ j.buildenv.2014.03.003.

Zhang, Y.J., Middel, A., Turner II, B.L., 2019. Evaluating the effect of 3D urban form on neighborhood land surface temperature using Google Street View and geographically weighted regression. Landsc. Ecol. 34, 681-697. https://doi.org/ 10.1007/s10980-019-00794-y.

Zheng, Z., Zhou, W., Yan, J., Qian, Y., Wang, J., Li, W., 2019. The higher, the cooler? Effects of building height on land surface temperatures in residential areas of Beijing. Phys. Chem. Earth 110, 149-156. https://doi.org/10.1016/ j.pce.2019.01.008. 